NASA Technical Memorandum 106912

\title{
Linearly Tapered Slot Antenna Impedance Characteristics
}

Rainee N. Simons

NYMA, Inc.

Brook Park, Ohio

and

Richard Q. Lee

Lewis Research Center

Cleveland, Ohio

Prepared for the

IEEE/AP-S International Symposium and USNC/URSI Radio Science Meeting sponsored by the IEEE Antennas and Propagation Society and

International Union of Radio Science

Newport Beach, California, June 18-23, 1995

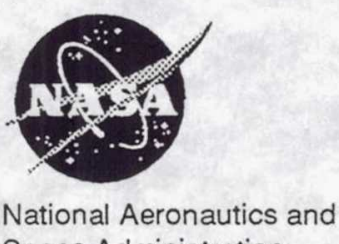

Space Administration 


\title{
LINEARLY TAPERED SLOT ANTENNA IMPEDANCE CHARACTERISTICS
}

\author{
Rainee N. Simons \\ NYMA, Inc. \\ 2001 Aerospace Parkway \\ Brook Park, Ohio 44142 \\ and \\ Richard Q. Lee \\ National Aeronautics and Space Administration \\ Lewis Research Center \\ Cleveland, Ohio 44135
}

\section{INTRODUCTION}

The linearly tapered slot antenna (LTSA) is a very useful antenna because of its simple construction, high gain and wide bandwidth (ref. 1). Previous experimental studies (refs. 2 and 3) emphasized the dependance of the beam width, directivity and gain on the flare length and angel of the LTSA. In addition we have previously demonstrated several novel techniques to feed a LTSA (ref. 4) and also studied the effect of a dielectric overlay on the LTSA beam width and gain (ref. 5). In all of the above investigations, the input impedance of the LTSA has been approximated to be the same as that of an equivalent biconical fin antenna (ref. 3). This approximation is valid only over a certain frequency band.

This paper demonstrates for the first time an accurate technique to determine the input impedance of a LTSA using a microwave wafer probe and a set of on-wafer Thru-Reflect-Line (TRL) slot line calibration standards. Experimental results are presented which show the variation of the input impedance as a function of the frequency with the semi-flare angle and flare length used as parameters.

\section{EXPERIMENTAL METHODOLOGY}

The LTSA is fabricated on a 0.01 in. thick RT/duroid $6010.5\left(\varepsilon_{\mathrm{T}}=10.5\right)$. The layout of the LTSA is shown in figure 1 . In this figure $\theta$ and $L$ represent the semi-flare angle and flare length respectively. The LTSA is excited through a short length of a slot line by a ground-signal microwave probe (Picoprobe Inc.) as shown in figure 2 . The slot line minimizes the interaction between LTSA input terminals and the parasitic associated with the probe tips.

The reflection coefficient of the LTSA is de-embedded from the measured reflection coefficient $\left(\mathrm{S}_{11}\right)$ at the input terminals of the slot line. The de-embedding is done with a HP $8510 \mathrm{C}$ Automatic Network Analyzer, a set of TRL on-wafer slot line calibration standards which is shown in figure 3 and the NIST de-embedding software (ref. 6). The software runs on a HP 9000 computer and controls the Network Analyzer.

\section{RESULTS AND DISCUSSIONS}

\section{LTSA with Constant Length}

The real and imaginary parts of the de-embedded LTSA input impedance $\operatorname{Re}\left(Z_{\text {in }}\right)$ and $\operatorname{Im}\left(Z_{\text {in }}\right)$ as a function of the frequency for $\theta=5^{\circ}$ and $L=1$ in. are shown in figures $4(a)$ and (b) respectively. The plots of $Z_{\text {in }}$ show a series of resonances over the frequency band. As the frequency varies from 2 to $26.5 \mathrm{GHz}$, the normalized length of the LTSA $\left(L / \lambda_{\mathrm{o}}\right)$ varies from $0.17 \lambda_{\mathrm{o}}$ to $2.24 \lambda_{\mathrm{o}}$, where $\lambda_{\mathrm{o}}$ is the free space wavelength. The corresponding variation in the normalized width of the mouth of the LTSA $\left(\mathrm{W} / \lambda_{\mathrm{o}}\right)$ is from $0.03 \lambda_{\mathrm{o}}$ to $0.4 \lambda_{\mathrm{o}}$. In a LTSA at the lower end of the frequency band, $W / \lambda_{\mathrm{o}}$ is very small and hence the electric field intensity is large which results in a large wave 
impedance. The large wave impedance in turn results in a large $\operatorname{Re}\left(\mathrm{Z}_{\text {in }}\right)$ for the first resonance mode, typically about $2500 \Omega$. On the other hand at the upper end of the frequency band, the effective aperture is large and hence $\operatorname{Re}\left(Z_{\text {in }}\right)$ is small, typically about $145 \Omega$ The minimum value of $\operatorname{Re}\left(\mathrm{Z}_{\text {in }}\right)$ (occurs between the resonances at the high end of the frequency band) is about $40 \Omega$ which is approximately half the value predicted in reference 2 .

Measurements on several other LTSAs with the same L but with $\theta$ progressively increased from $5^{\circ}$ up to $20^{\circ}$ in steps of $2.5^{\circ}$ show that at the lower end of the frequency band $\operatorname{Re}\left(Z_{\text {in }}\right)$ decreases as $\theta$ increases. These results also support the above discussion. Figures $5(a)$ and (b) show $\operatorname{Re}\left(Z_{\text {in }}\right)$ and $\operatorname{Im}\left(Z_{\text {in }}\right)$ respectively for $\theta=20^{\circ}$. From figure $5(a), \operatorname{Re}\left(Z_{\text {in }}\right)$ is about 650 and $145 \Omega$ at the low and the high end of the frequency band respectively. The minimum value of $\operatorname{Re}\left(Z_{\text {in }}\right)$ is about $85 \Omega$ which is about the same as predicted in reference 2 .

\section{LTSA with Constant Semi-Flare Angle}

Figures $6(a)$ and (b) present the $\operatorname{Re}\left(Z_{\text {in }}\right)$ and $\operatorname{lm}\left(Z_{\text {in }}\right)$ respectively for $\theta=10^{\circ}$ and $L=3$ in. In this case $L / \lambda_{0}$ is about three times larger than the previous case and consequently there are about three times more resonances. For this LTSA, the $\operatorname{Re}\left(Z_{\text {in }}\right)$ is initially large and is as high as $1300 \Omega$ when $L / \lambda_{0}=1.15 . \operatorname{Re}\left(Z_{\text {in }}\right)$ reduces as $L / \lambda_{0}$ increases and is in the range of 55 to $130 \Omega$ for $L / \lambda_{0}>3.6$.

\section{CONCLUSIONS}

An experimental technique to de-embed the input impedance of a LTSA from the measured reflection coefficient has been presented. The results show that the input impedance is dependent on the semi-flare angle and the length of the LTSA. The $\operatorname{Re}\left(\mathrm{Z}_{\text {in }}\right)$ is large, on the order of few thousand ohms, when the electrical length of the LTSA is small. However for an electrically large LTSA, $\operatorname{Re}\left(\mathrm{Z}_{\text {in }}\right)$ is in the range of 55 to $130 \Omega$ These results have potential applications in the design of broad band impedance matching networks for LTSAs.

\section{REFERENCES}

1. Prasad, S.N., and Mahapatra, S.: A Novel MIC Slot-Line Antenna, 9th European Microwave Conference Proc., pp. 120-123, 1979.

2. Yngvesson, K.S., et al.: The Tapered Slot Antenna- A New Integrated Element for Millimeter-Wave Applications, IEEE Trans. Microwave Theory Tech., vol. 37, no. 2, pp. 365-374, Feb. 1989.

3. Yngvesson, K.S., et al.: Endfire Tapered Slot Antennas on Dielectric Substrates, IEEE Trans. Antennas and Propagation, vol. AP-33, no. 12, pp. 1392-1400, Dec. 1985.

4. Simons, R.N., et al.: New Technique for Exciting LinearlyTapered Slot Antennas with Coplanar waveguide, Electron. Lett., vol. 28, no. 7, pp. 620-621, March 1992.

5. Simons, R.N., and Lee, R.Q.: Linearly Tapred Slot Antenna with Dielectric Superstrate, 1993 IEEE Antennas and Propagation Inter. Symp. Dig., vol. 3, pp. 1482-1485

6. NIST De-embedding Software, Program DEEMBED, rev. 4.04, 1994. 


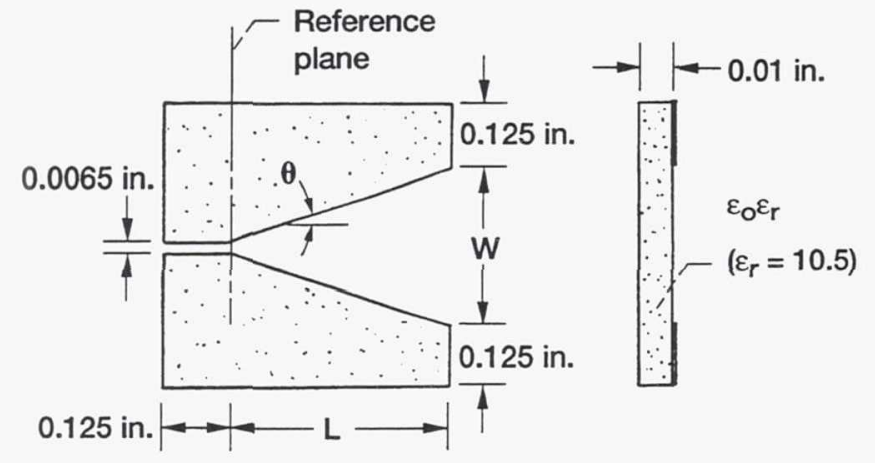

Figure 1.-Schematic of the LTSA.

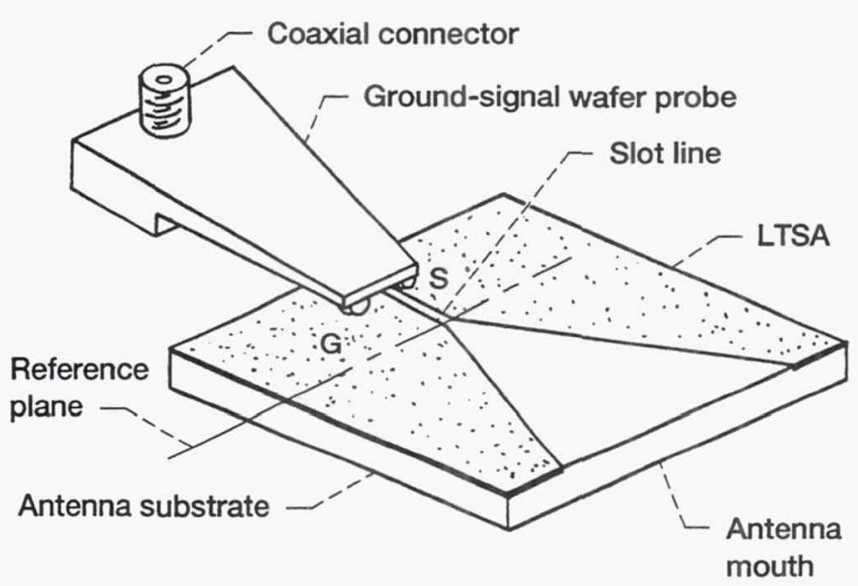

Figure 2.-Experimental set-up.

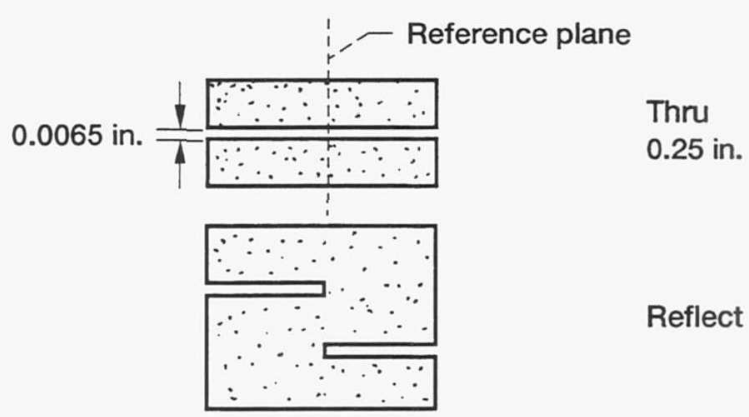

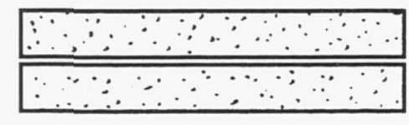
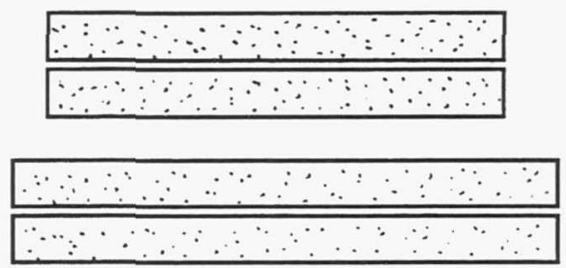

Delay line \#3 0.45 in.

Figure 3.-TRL on-wafer slot line calibration standards. 

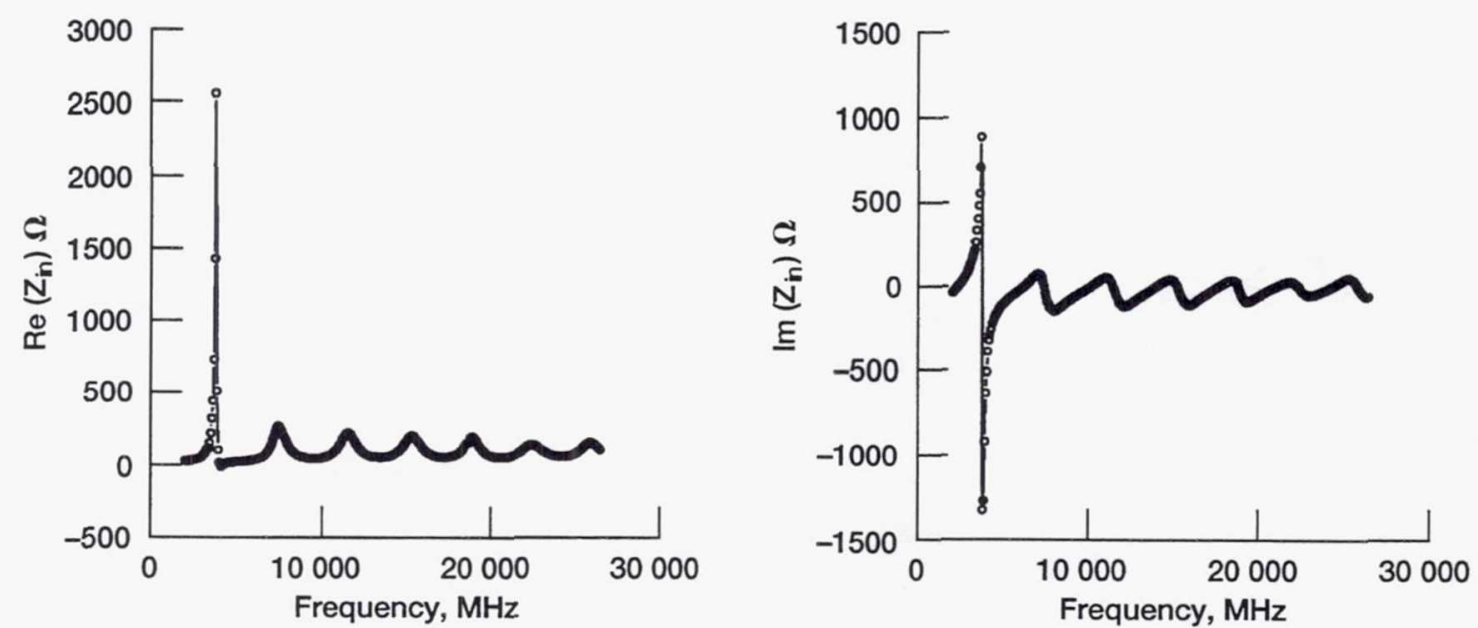

Figure 4.-Real and imaginary part of the input impedance $\left(\theta=5^{\circ}, \mathrm{W}=0.179\right.$ inch, $\left.\mathrm{L}=1 \mathrm{inch}\right)$.
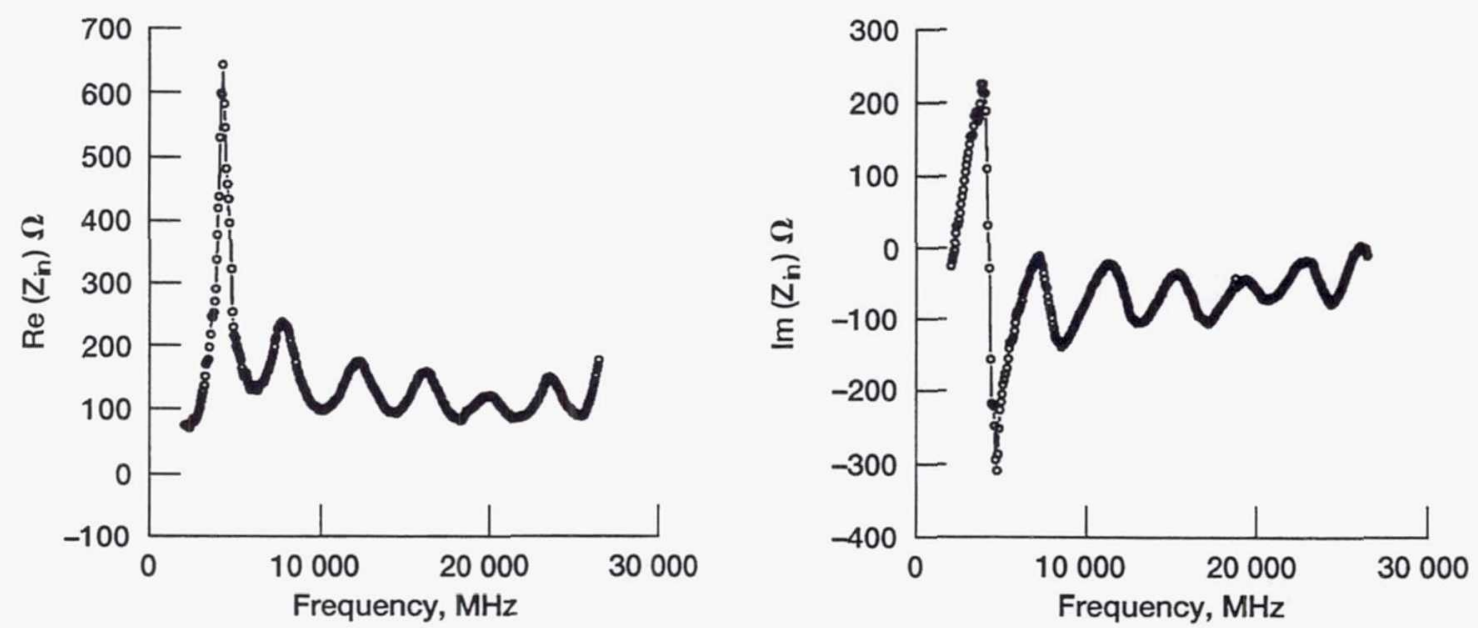

Figure 5.-Real and imaginary part of the input impedance $\left(\theta=20^{\circ}, \mathrm{W}=0.732\right.$ inch, $\mathrm{L}=1$ inch).
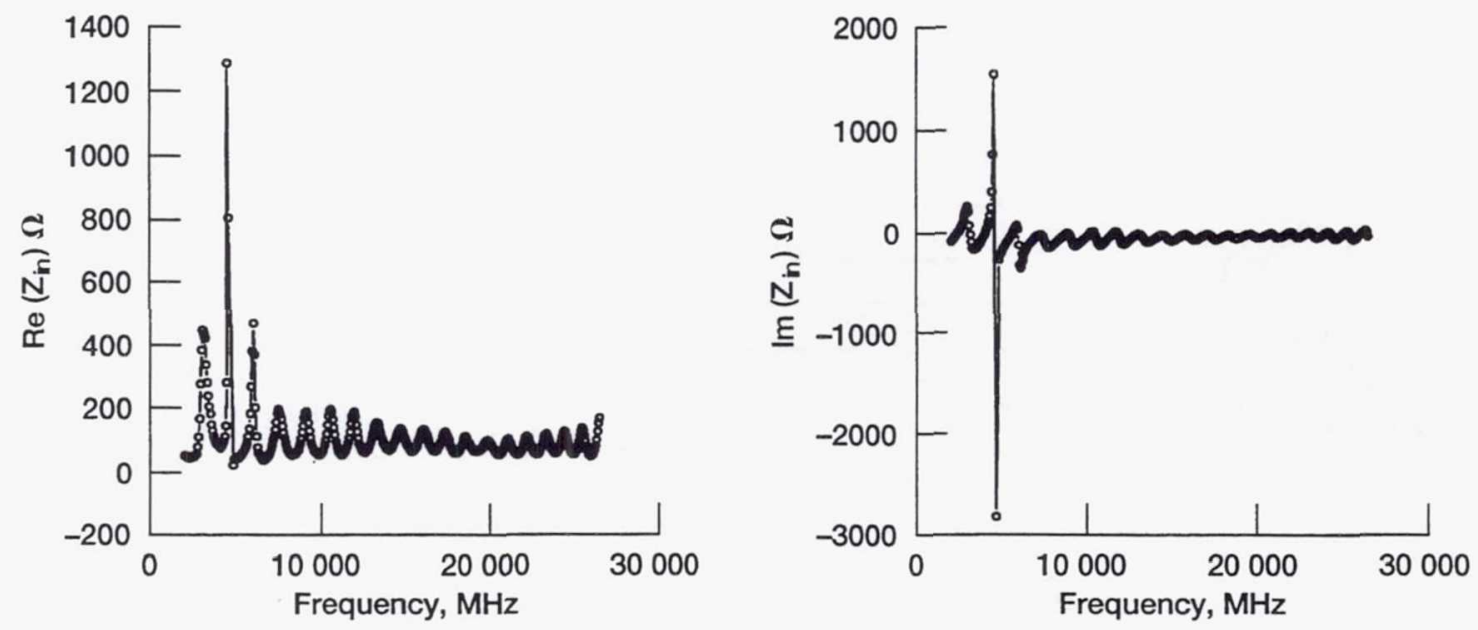

Figure 6.-Real and imaginary part of the input impedance $\left(\theta=10^{\circ}, W=1.06\right.$ inch, $L=3$ inch). 
Public reporting burden for this collection of information is estimated to average 1 hour per response, including the time for reviewing instructions, searching existing data sources, gathering and maintaining the data needed, and completing and reviewing the collection of information. Send comments regarding this burden estimate or any other aspect of this Davis Highway, Suite 1204, Arlington, VA 22202-4302, and to the Office of Management and Budget, Paperwork Reduction Project (0704-0188), Washington, DC 20503.

\begin{tabular}{|l|l|l|}
\hline 1. AGENCY USE ONLY (Leave blank) & $\begin{array}{c}\text { 2. REPORT DATE } \\
\text { May } 1995\end{array}$ & $\begin{array}{r}\text { 3. REPORT TYPE AND DATES COVERED } \\
\text { Technical Memorandum }\end{array}$ \\
\hline
\end{tabular}

4. TITLE AND SUBTITLE

5. FUNDING NUMBERS

Linearly Tapered Slot Antenna Impedance Characteristics

6. AUTHOR(S)

WU-506-44-2C

Rainee N. Simons and Richard Q. Lee

7. PERFORMING ORGANIZATION NAME(S) AND ADDRESS(ES)

8. PERFORMING ORGANIZATION REPORT NUMBER

National Aeronautics and Space Administration

Lewis Research Center

Cleveland, Ohio 44135-3191

E-9614

9. SPONSORING/MONITORING AGENCY NAME(S) AND ADDRESS(ES)

10. SPONSORING/MONITORING AGENCY REPORT NUMBER

National Aeronautics and Space Administration

Washington, D.C. 20546-0001

NASA TM-106912

11. SUPPLEMENTARY NOTES

Prepared for the IEEE/AP-S International Symposium and USNC/URSI Radio Science Meeting sponsored by the IEEE Antenna and Propagation Society and International Union of Radio Science, Newport Beach, California, June 18-23, 1995. Rainee N. Simons, (216) 433-3462, NYMA, Inc., 2001 Aerospace Parkway, Brook Park, Ohio (work funded by NASA Contract NAS3-27186); and Richard Q. Lee, NASA Lewis Research Center. Responsible person, Richard Q. Lee, organization code 5640, (216) 433-3489.

\begin{tabular}{l|l} 
12a. DISTRIBUTION/AVAILABILITY STATEMENT & 12b. DISTRIBUTION CODE
\end{tabular}

Unclassified - Unlimited

Subject Category 33

This publication is available from the NASA Center for Aerospace Information, (301) 621-0390.

13. ABSTRACT (Maximum 200 words)

The paper presents for the first time an experimental technique to de-embed the input impedance of a LTSA from the measured reflection coefficient. The results show that the input impedance is dependent on the semi-flare angle and the length of the LTSA. The $\operatorname{Re}\left(\mathrm{Z}_{\text {in }}\right)$ is large when the electrical length of the LTSA is small and is on the order of few thousand ohms. However for an electrically large LTSA the $\operatorname{Re}\left(Z_{\text {in }}\right)$ is in the range of 55 to $130 \mathrm{ohms}$. These results have potential applications in the design of broad band impedance matching networks for LTSA.

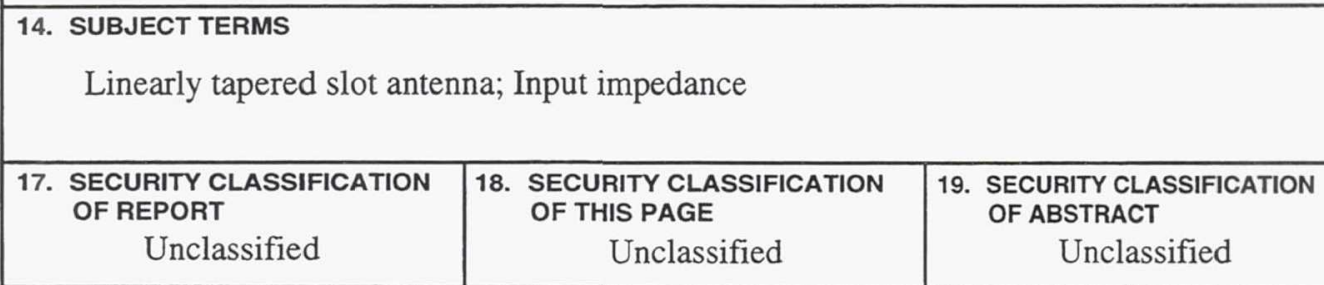

